NISTIR 89-3926

\title{
APPARATUS FOR MEASURING \\ HIGH-FLUX HEAT TRANSFER \\ IN RADIATIVELY HEATED \\ COMPACT EXCHANGERS
}

Douglas A. Olson

National Institute of Standards and Technology

U.S. Department of Commerce

Boulder, Colorado 80303-3328

October 1989 



\section{APPARATUS FOR MEASURING HIGH-FLUX HEAT TRANSFER \\ IN RADIATIVELY HEATED COMPACT EXCHANGERS}

Douglas A. Olson

Chemical Engineering Science Division

Center for Chemical Engineering

National Engineering Laboratory

National Institute of Standards and Technology

Boulder, Colorado 80303-3328

October 1989

Sponsored by

National Aeronautics and Space Administration

Langley Research Center

Hampton, Virginia 23665

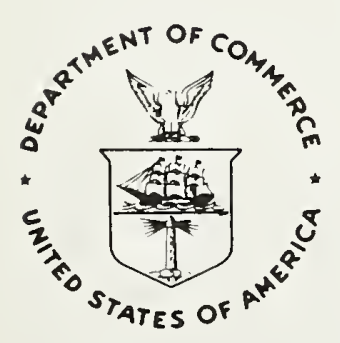



List of

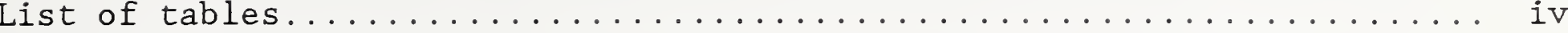

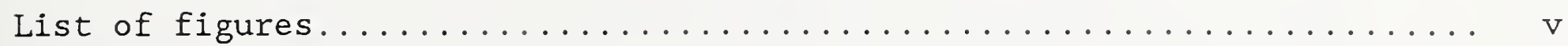

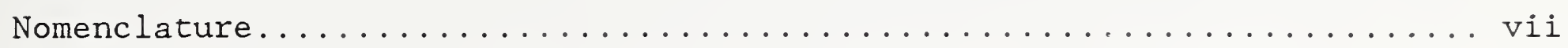

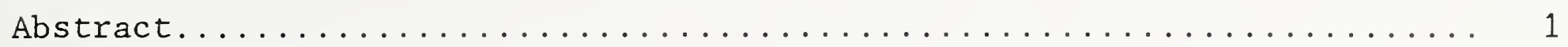

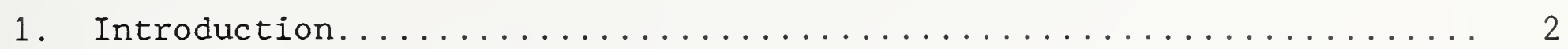

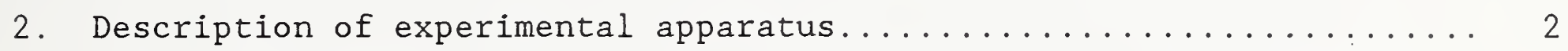

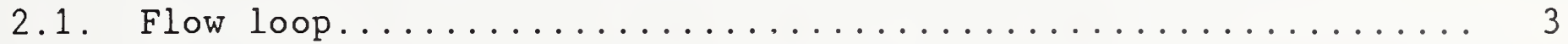

2.2. Instrumentation......................... 4

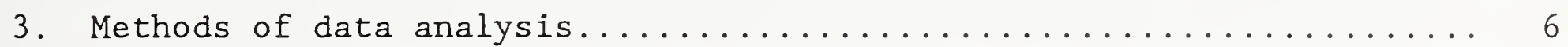

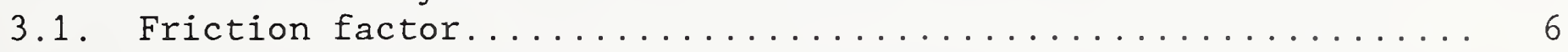

3.2. Heat transfer coefficient...................... 7

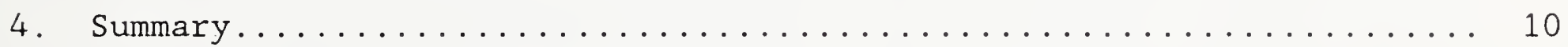

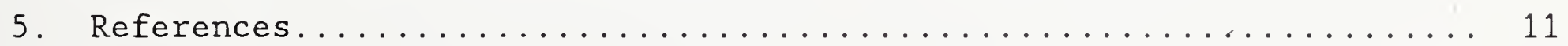

Appendix A. Calibration of the heat-flux distribution within the

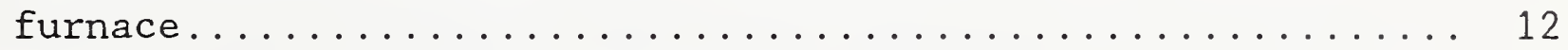

A.1. Description of the calibration apparatus............... 12

A.2. Operation of the heat flow meters................... 13

A.3. Methods of data analysis....................... 14

A.4. Results of the calibration..................... 16

A.5. Uncertainty in the furnace heat flux calibration.......... 19 
List of tables

Table 1. Uncertainties in experimental measurements and gas properties

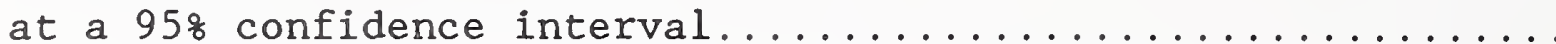

Table A.1. Summary of furnace calibration experiments............ 17

Table A.2. Furnace heat flux distribution function, $\mathrm{f}_{\mathrm{q}} \ldots \ldots \ldots \ldots$ 
List of figures

Figure 1. Pin-fin heat exchanger for NASP application (separated view).. 20

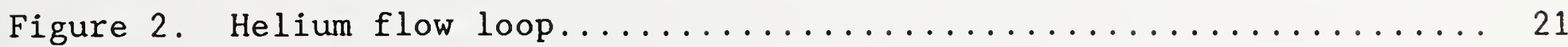

Figure 3. Specimen furnace. Inlet and outlet gas temperatures are measured at points 0 and 1; upstream and downstream pressures

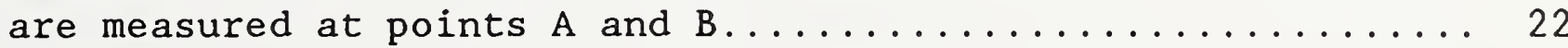

Figure 4. Technique for mounting thermocouples on pin-fin specimens.... 23

Figure A.1. Calibration specimen in furnace................. 24

Figure A.2. Lay-out of heat flow meters on calibration specimen...... 25

Figure A.3. Traverse of normalized heat flow along $y$ direction at $x=0$. Shown are data from tests 2 and 3 , heater voltages 35.38 and 19.98. "*" is meter 1 , and "o" is meter $2 \ldots \ldots 26$

Figure A.4. Traverse of normalized heat flow along $x$ direction at $y=0$ for heater voltages greater than 29\%. Shown are data from test 2 ( 35.38 voltage, "*"), test 4 (50.8\% voltage, "o"), and test 11 (29.3\% voltage, " $\Delta ")$. The smooth curve is the curve fitted to the normalized heat flow data ( $j$ function), which has a standard deviation of $0.5 \% \ldots \ldots \ldots \ldots \ldots \ldots \ldots$

Figure A.5. Traverse of normalized heat flow along $\mathrm{x}$ direction at $\mathrm{y}=0$ for heater voltages less than 29\%. Shown are data from test 6 (20.48 voltage, "*"), test 9 (20.28 voltage, "o"), and test 10 (24.5\% voltage, " $\Delta$ "). The smooth curve is the curve fitted to the normalized heat flow data ( $j$ function), which has a standard deviation of $0.38 \ldots \ldots \ldots \ldots \ldots \ldots \ldots$ 

$A=$ upstream location of pressure tap

$A_{f}=$ flow normal area $=V_{0} / L$

$A_{n}=$ specimen normal area

$A_{w}=$ wetted wall area (total wall area exposed to fluid)

$B=$ downstream location of pressure tap

$\mathrm{c}_{\mathrm{p}}=$ specific heat at constant pressure

$D_{h}=$ specimen hydraulic diameter

$$
=4 \mathrm{~V}_{0} / \mathrm{A}_{\mathrm{w}}
$$

$\mathrm{f}=$ friction factor

$f=$ normalized heat flux on target

$\mathrm{f}_{\mathrm{q}}(\mathrm{x}, \mathrm{y}, \mathrm{v})=$ heat flux distribution function

$\mathrm{G}=$ mass flow rate per unit flow normal area

$=\dot{\mathrm{m}} / \mathrm{A}_{\mathrm{f}}=\rho \mathrm{V}$

$h=$ heat transfer coefficient

$\mathrm{h}=$ enthalpy

$j(x, y, v)=$ normalized heat flow through heat flow meter

$j_{t}(x, y, v)=$ heat flow through heat flow meter

$\mathrm{k}=$ thermal conductivity

$\mathrm{K}=$ heat flow meter calibration constant

$\mathrm{L}=$ length of specimen

$\dot{\mathrm{m}}=$ mass flow rate

$\mathrm{Nu}=$ Nusselt number $=\mathrm{h} \cdot \mathrm{D}_{\mathrm{h}} / \mathrm{k}$

$P=$ pressure

$\operatorname{Pr}=\operatorname{Prand} t \mathrm{l}$ number $=\mu \cdot \mathrm{c}_{\mathrm{p}} / \mathrm{k}$

$\mathrm{q}(\mathrm{x}, \mathrm{y}, \mathrm{v})=$ local heat flux based on area normal to the furnace target

$\mathrm{Q}_{\mathrm{m}}=$ heat leak to manifolds through insulation

$\mathrm{Q}_{\mathrm{m}}$, in $=$ heat leak to inlet manifold

$\mathrm{Q}_{\mathrm{px}}=$ fraction of total heat flow on specimen added up to position $\mathrm{x}$

= integration of furnace calibration function $\mathrm{f}_{\mathrm{q}}, 0$ to $\mathrm{x}$

$\mathrm{Q}_{\mathrm{T}}=$ total heat transfer to specimen

$\mathrm{q}_{\mathrm{w}}=$ local heat flux (heat flow per unit area) into the cooling fluid based on total wetted-wall area of the specimen

$r=$ recovery factor $=\operatorname{Pr}^{1 / 3}$ for turbulent flow

$\operatorname{Re}=$ Reynolds number $=\rho \mathrm{VD}_{\mathrm{h}} / \mu$

$\mathrm{T}=$ temperature

$\mathrm{T}_{\mathrm{aw}}=$ cooling fluid adiabatic wall temperature

$\mathrm{T}_{\mathrm{f}}=$ local bulk fluid temperature

$\mathrm{T}_{\mathrm{r}}=$ Eckert reference temperature

$\mathrm{T}_{\mathrm{w}}=$ specimen wall temperature

$\mathrm{v}=$ heater voltage

$\mathrm{V}=$ velocity

$\mathrm{V}(\mathrm{x}, \mathrm{y}, \mathrm{v})=$ measured heat flow meter voltage

$\mathrm{V}_{\mathrm{o}}=$ open volume in specimen

$\mathrm{w}=$ heat flow meter half-width

$\mathrm{x}=$ position coordinate parallel to flow direction

$\mathrm{x}_{0}=$ furnace target half-width $=\mathrm{L} / 2$

$y=$ position coordinate perpendicular to flow direction

$\beta=$ coefficient of thermal expansion

$\sigma=$ standard deviation 
$\mu=$ dynamic viscosity

$\rho=$ density

$0=$ location in inlet manifold of PRT

1 = location in outlet manifold of PRT 
Apparatus for Measuring High-Flux

Heat Transfer in Radiatively Heated Compact Exchangers

\author{
Douglas A. Olson \\ Chemical Engineering Science Division \\ National Institute of Standards and Technology \\ Boulder, CO 80303-3328
}

\begin{abstract}
We describe an apparatus which can deliver uniform heat flux densities of up to $80 \mathrm{~W} / \mathrm{cm}^{2}$ over an area $7.8 \mathrm{~cm}$ by $15.2 \mathrm{~cm}$ for use in measuring the heat transfer and pressure drop in thin (6 $\mathrm{mm}$ or less), compact heat exchangers. Helium gas at flow rates of 0 to $40 \mathrm{~kg} / \mathrm{h}$ and pressures to $6.9 \mathrm{MPa}$ (1000 psi) is the working fluid. We describe the instrumentation used in the apparatus and the methods for analyzing the data. We will use the apparatus initially to test the performance of prototype cooling jackets for the engine struts of the National Aerospace Plane (NASP).

Key words: apparatus; compact heat exchanger; convection heat transfer; friction factor; high temperature; National Aerospace Plane; pin-fin; radiative furnace.
\end{abstract}

This work was funded by NASA Langley Research Center under contract L7400C. 
Research at NASA on vehicles for hypersonic flight has been active since the 1960's (Shore, 1986). The renewed interest in developing a National Aerospace Plane (NASP) requires solving many demanding heat transfer problems associated with the anticipated high heat fluxes on various components. The problem of interest motivating this work is the cooling of the engine struts. Due to aerodynamic heating associated with the combustion of the hydrogen fuel, along with radiation from the fuel combustion, the engine struts are expected to receive a heating load in excess of $2000 \mathrm{~W} / \mathrm{cm}^{2}$ (Scotti et al., 1988). NASA plans to cool the struts by attaching a cooling jacket heat exchanger to the surface facing the high heat flux. Hydrogen gas will flow through the cooling jacket, absorbing the heat before entering the engine.

The anticipated conditions are that the hydrogen gas will enter the heat exchangers at $56 \mathrm{~K}$ and $6.9 \mathrm{MPa}$ (1000 psi), and exit at $890 \mathrm{~K}$ and $4.8 \mathrm{MPa}$ (700 psi). The heat exchangers are expected to be thin perpendicular to the flow direction ( $6 \mathrm{~mm}$ or less) to add minimal weight and thickness to the struts. Small flow passages will also produce high rates of convective heat transfer, which will reduce the exchanger temperatures. Reynolds numbers are expected to be in the range 10000 to 30000, with the variation due to the flow rate and the specific design of the flow passage. Because of the small flow passages and high heating rates, the heat transfer performance of the prototype heat exchangers is beyond the range of past experimental work and correlations.

A leading candidate for the cooling jacket is the "pin-fin" heat exchanger (fig. 1). This design is being considered based on fabrication techniques, structural considerations, and the anticipated heat transfer performance (Buchmann et al., 1985). Nickel 201 is one of the proposed materials, due to its high ductility and high thermal conductivity. A pin-fin heat exchanger consists of a closely spaced channel with pins connecting the top and bottom surfaces. The pin-fins increase the heat transfer area; by promoting turbulence they also increase the local heat transfer coefficient. Compared to other compact heat exchangers, the pin-fin configuration has high heat transfer per unit volume, but also a large pressure drop (Kays and London, 1964). Pin-fin heat exchangers have been used for cooling turbine blades in gas turbines, and most of the existing correlations are based on work for that application (Armstrong and Winstanley, 1987).

The objective of this work was to design and build an experimental apparatus which could test prototype heat exchangers at some of the conditions anticipated for the NASP application. Test results would be heat transfer performance and pressure drop as a function of Reynolds number, heating rate, and flow geometry. The apparatus will be used initially to test pin-fin heat exchangers, and in the future will be capable of testing any flat, compact heat exchanger which can conform to the furnace dimensions.

\section{Description of the experimental apparatus}

The experimental apparatus has been designed to initially test a subset of the conditions required for the NASP application. Those conditions are (1) 
a heating rate of $0-80 \mathrm{~W} / \mathrm{cm}^{2} ;$ (2) an inlet temperature of $300 \mathrm{~K}$; (3) a cooling-gas pressure of $6.9 \mathrm{MPa}$ at the inlet; and (4) an outlet temperature of $810 \mathrm{~K}$. The size of specimen which can be tested is $7.8 \mathrm{~cm}$ wide by $15.2 \mathrm{~cm}$ long. Because of the similarities in specific heat, thermal conductivity, and dynamic viscosity between helium and hydrogen, helium will be the first cooling gas tested. The Reynolds numbers and temperature rise from specimen inlet to outlet can be matched between helium and hydrogen. As the taking of data progresses, indicating the critical experimental parameters, flow loop components can be added which yield cryogenic inlet conditions or higher heating rates. Hydrogen gas will be tested after moving the apparatus to a special site for hazardous tests and adding hydrogen-safety features.

\subsection{Flow loop}

The helium flow loop is shown in figure 2, with the details of the specimen furnace section in figure 3. Helium gas at $13.8 \mathrm{MPa}$ (2000 psi) is supplied from a tube trailer outside the laboratory. The tube trailer contains $1100 \mathrm{~m}^{3}$ of gas (STP). Valve \#1 at the trailer isolates the gas from the $1.2 \mathrm{~cm}$ diameter high pressure copper piping to the laboratory. A second shut-off valve (\#2) within the laboratory isolates the inlet piping from the portion within the laboratory. With valves \#1 and \#2 open, gas flows from the trailer, through the inlet piping, and is filtered before entering the domeloaded pressure regulator (valve \#3). The regulator sets the flow pressure downstream of the regulator to the value of an external control pressure, 6.9 MPa (1000 psi) or less. A pressure relief valve downstream of the regulator, set at $8.3 \mathrm{MPa}$ (1200 psi), prevents system over-pressure. The gas flows through stainless steel tubing, $1.9 \mathrm{~cm}$ OD and $0.21 \mathrm{~cm}$ wall, from the pressure regulator to the furnace.

Within the furnace (fig. 3), the gas flows into an inlet distribution manifold (347 stainless steel) which directs the gas to the heat exchanger specimen. A similar distribution manifold collects the gas exiting the specimen and directs it to the outlet tubing. The heat exchanger specimen is brazed into the space between the manifolds. The specimens are located in the target area of the furnace, which delivers radiant heat to the specimens and raises the temperature of the helium as it flows through the specimen.

The furnace consists of a high-intensity radiant infrared heater, surrounded by refractory insulation, $5 \mathrm{~cm}$ thick or greater, which directs and re-radiates the heat from the heater to the specimen. The heater contains six high-temperature infrared lamps mounted in an aluminum housing. Filtered shop air at $0.85 \mathrm{~m}^{3} / \mathrm{min}(30 \mathrm{cfm})$ or greater cools the heater lamps, and water at 4 $\mathrm{kg} / \mathrm{min}$ ( $1 \mathrm{gpm}$ ) or greater cools the housing. The radiant heater is powered by a phase-angle power controller which uses $480 \mathrm{VAC}$, single phase, and $75 \mathrm{~A}$ at full power setting. At the maximum heat flux setting, the refractory walls reach an estimated temperature of $1760^{\circ} \mathrm{C}\left(3200^{\circ} \mathrm{F}\right)$.

Downstream of the furnace section, the hot gas flows through more stainless steel tubing $(1.9 \mathrm{~cm}$ OD, $0.21 \mathrm{~cm}$ wall) to a cooling coil (5.5 $\mathrm{m}$ of the same tubing) immersed in a water bath. The water bath cools the helium temperature to $30^{\circ} \mathrm{C}$ or less. The rate of gas flow is manually adjusted at the bath outlet by valve \#4, which also drops the gas pressure to atmospheric 
pressure. Beyond the valve, helium flow rate is measured with a heated-tube thermal mass flow meter, with \pm 18 uncertainty in the reading (at a 958 confidence level). After exiting the flow meter the gas flows into an exhaust line of $5 \mathrm{~cm}$ copper tubing, and is vented outside the laboratory.

\subsection{Instrumentation}

Measurements are made of temperature of the gas in the inlet and outlet manifolds, gas pressure in the specimen, specimen temperatures, and the aforementioned gas flow rate. Uncertainties in the measured quantities are summarized in Table 1.

Table 1. Uncertainties in experimental measurements and gas properties at a $95 \%$ confidence interval

\begin{tabular}{|c|c|c|c|}
\hline Measurement/Property & Technique & $\begin{array}{l}\text { Major Source } \\
\text { of Uncertainty }\end{array}$ & $\begin{array}{l}\text { Magnitude } \\
\text { of Uncertainty }\end{array}$ \\
\hline Gas Flow Rate & $\begin{array}{l}\text { Thermal Mass Flow } \\
\text { Meter }\end{array}$ & Meter Calibration & \pm 18 \\
\hline Heat Flux & $\begin{array}{l}\text { Calibration of } \\
\text { Furnace }\end{array}$ & Heat Flow Meter & \pm 48 \\
\hline $\begin{array}{l}\text { Gas Inlet and } \\
\text { Outlet Temperatures }\end{array}$ & $\begin{array}{l}\text { Platinum Resis- } \\
\text { tance Thermometer }\end{array}$ & Radiation & $\pm 0.5 \mathrm{~K}$ \\
\hline Gas Pressure & $\begin{array}{l}\text { Pressure Trans- } \\
\text { ducer }\end{array}$ & Calibration & $\begin{array}{l} \pm 0.258 \text { of } \\
\text { full scale }\end{array}$ \\
\hline Specimen Temperature & $\begin{array}{l}\text { Type-N Thermo- } \\
\text { couple }\end{array}$ & $\begin{array}{l}\text { Wire Calibration, } \\
\text { Installation }\end{array}$ & $\begin{array}{l}\text { greater of } \\
\pm 0.48 \text { or } 1.1 \mathrm{~K}\end{array}$ \\
\hline $\begin{array}{l}\text { Gas Temperature in } \\
\text { Specimen }\end{array}$ & $\begin{array}{l}\text { Integrate Energy } \\
\text { Equation }\end{array}$ & $\begin{array}{l}\text { Heat Flux } \\
\text { Uncertainty }\end{array}$ & \pm 18 of $\mathrm{T}_{1}-\mathrm{T}_{0}$ \\
\hline Gas Density & $\begin{array}{l}\text { Thermodynamic } \\
\text { Function }\end{array}$ & Function Accuracy & $\pm 0.1 \%$ \\
\hline Gas Enthalpy & $\begin{array}{l}\text { Thermodynamic } \\
\text { Function }\end{array}$ & Function Accuracy & \pm 0.28 \\
\hline Gas Specific Heat & $\begin{array}{l}\text { Thermodynamic } \\
\text { Function }\end{array}$ & Function Accuracy & \pm 58 \\
\hline Gas Viscosity & $\begin{array}{l}\text { Thermodynamic } \\
\text { Function }\end{array}$ & Function Accuracy & \pm 108 \\
\hline $\begin{array}{l}\text { Gas Thermal } \\
\text { Conductivity }\end{array}$ & $\begin{array}{l}\text { Thermodynamic } \\
\text { Function }\end{array}$ & Function Accuracy & \pm 38 \\
\hline
\end{tabular}


We determined the heat flux distribution on the specimen by calibrating the furnace prior to inserting the specimen. The heat flux distribution is defined as the local heat flux as a function of position over the furnace target and as a function of heater lamp voltage. Details of the furnace calibration are given in appendix A. The uncertainty in the heat flux is estimated as \pm 48 .

The gas inlet and outlet temperatures are measured with platinum resistance thermometers (PRTs), $0.48 \mathrm{~cm}$ diameter, inserted in the gas manifolds at locations 0 and 1 of figure 3 . The uncertainty in the thermometer calibration is $\pm 0.08 \mathrm{~K}$; the uncertainty introduced by the digital voltmeter is $\pm 0.036 \mathrm{~K}$. Radiation errors in the thermometers are estimated as less than $\pm 0.5 \mathrm{~K}$, while conduction errors in the thermometers are estimated as less than $\pm 0.01 \mathrm{~K}$. The gas pressure at the specimen inlet (location $A$ in figure 3 ) is measured with a variable-reluctance pressure transducer.

Pressure difference between the specimen inlet and outlet (A to B) is measured with a second pressure transducer, also a variable-reluctance type with interchangeable diaphragms. The uncertainty in the calibration of both is $\pm 0.25 \%$ of full scale. Uncertainty introduced by the voltmeter is $\pm 0.011 \%$ of the pressure reading.

Specimen temperatures will be measured with type- $\mathrm{N}$ thermocouple wire, wire diameter $0.25 \mathrm{~mm}$. An array of thermocouples, 25 or more depending on the specimen design, will be spot-welded to the side opposite the radiant heat flux (insulated-side). Temperatures measured at the insulated-side thermocouples will be used to determine the heat transfer coefficient. The relative uncertainty from pair-to-pair is \pm 0.48 of the reading or $\pm 1.1 \mathrm{~K}$, whichever is greater. At the maximum expected specimen temperature this is $\pm 2.1 \mathrm{~K}$. Estimates of the heated-side temperature will be made with type-N thermocouples mounted in a fashion shown in figure 4, which is the method for the pin-fin specimen. Each wire of the pair is spot-welded to the heated surface, with the lead extending out a hole drilled through the specimen. For the pin-fin specimen, the holes will be drilled through the center of a pin. The thermocouple circuit is completed by the specimen wall between the two wires. A quartz sleeve, $0.5 \mathrm{~mm}$ diameter, electrically insulates the wire from the wall of the hole. Because a portion of the pin is removed and replaced by wire plus quartz, each of which has a lower thermal conductivity than the pin (nickel), a pin with a wire mounted in it will be hotter than a pin with no wire mounted in $i t$. We estimated the magnitude of this temperature rise from a finite-element analysis as $2-5 \mathrm{~K}$ at a radiant heat flux of $50 \mathrm{~W} / \mathrm{cm}^{2}$.

All type-N thermocouples will be connected to an isothermal reference box. We measured the temperature uniformity of the reference box as $\pm 0.05 \mathrm{~K}$ or better. Copper conductor wire runs from the reference box to the data scanner. The temperature of the reference box is measured with a platinum resistance thermometer (PRT). Using the box PRT sensor for the reference temperature, we compared temperatures indicated by thermocouples connected to six terminals in the reference box with temperatures indicated by the gas inlet and outlet PRTs. All sensors were immersed in a stirred water bath at $20-30^{\circ} \mathrm{C}$. This provided a system accuracy for the reference box plus PRT. The agreement in temperature between the thermocouples and gas PRTs was better than $\pm 0.06 \mathrm{~K}$. 
All instrument signals are multiplexed through an automated scanner and measured on a digital voltmeter. The scanner and voltmeter are controlled with a personal computer through an IEEE 488 bus. Raw signals are stored on a hard disk and copied to floppy disk for backup. Signals are converted to engineering units and the data analyzed at the completion of an experimental run. Some signal readings are converted immediately to engineering units and displayed on the video terminal to assist in monitoring and operating the experiment. The measurement uncertainties introduced by the data acquisition system have been included in the stated uncertainties of each sensor.

\section{Methods of data analysis}

The data required to evaluate the performance of the heat transfer specimens are the heat transfer coefficient, $h$, and the friction factor, $f$.

\subsection{Friction factor}

The friction factor results from an integration of the one-dimensional momentum equation in the flow direction:

$$
P_{A}-P_{B}=G^{2}\left(1 / \rho_{B}-1 / \rho_{A}\right)+\left(2 G^{2} / D_{h}\right) \int_{A}^{B}(f / \rho) d x,
$$

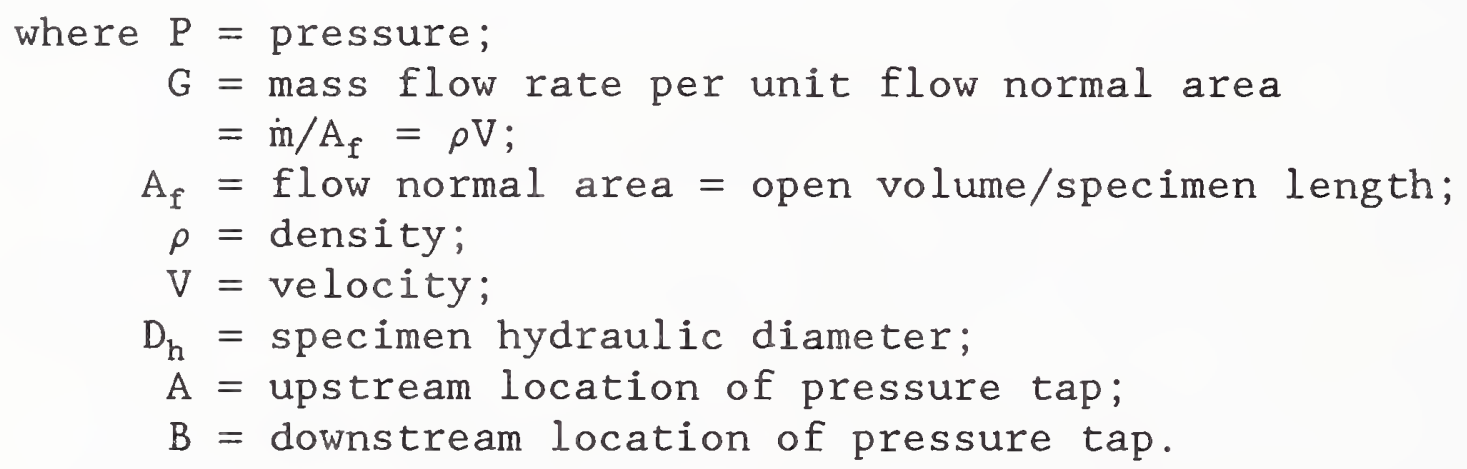

The first term on the right hand side of the equation is the pressure change due to flow acceleration, and the second term is the pressure drop due to frictional effects. For the pin-fin specimens, the hydraulic diameter is given by (VanFossen, 1982):

$$
D_{h}=4 V_{0} / A_{w},
$$

where $V_{0}=$ open volume in specimen;

$A_{\mathrm{w}}=$ wetted wall area (total wall area exposed to fluid).

This definition is appropriate when the pin height, pin diameter, and pin-topin separation are of the same order, as all are likely significant in generating turbulence which drives the pressure drop and heat transfer.

If the density change is small compared to the absolute density, and the pressure drop through the specimen is linear, then the integral can be approximated as a constant and the resulting equation for $f$ is: 


$$
f=\frac{P_{A}-P_{B}-G^{2}\left(1 / \rho_{B}-1 / \rho_{A}\right)}{2\left(G^{2} / \rho\right) \cdot\left(L / D_{h}\right)},
$$

with $\rho=\left(\rho_{\mathrm{A}}+\rho_{\mathrm{B}}\right) / 2$.

The density change criterion is met when the gas flows through the specimen without being heated, but when the specimen is heated the exit density can be less than half the entrance density and eq ( 3 ) is not valid. The friction factor is calculated for a series of tests with flow rate as the variable but with no heating, and a functional dependence of $f$ on Reynolds number is developed, where the Reynolds number is defined as

$$
\operatorname{Re}=\rho \mathrm{VD}_{\mathrm{h}} / \mu \text {. }
$$

Then, for experiments with specimen heating, the density and Reynolds number (evaluated using the local gas temperature and pressure) are calculated as a function of $\mathrm{x}$. The integral in eq (1) is evaluated to calculate the pressure drop from A to B, which is checked against the measured pressure drop. This provides a technique for evaluating if $f$ depends on more than Reynolds number alone.

\subsection{Heat transfer coefficient}

The heat transfer coefficient, $h$, is defined through the equation

$$
\mathrm{q}_{w}=\mathrm{h} \cdot\left(\mathrm{T}_{\mathrm{w}}-\mathrm{T}_{\mathrm{aw}}\right)
$$

where $\mathrm{q}_{w}=$ local heat flux (heat flow per unit area) into the cooling fluid based on total wetted-wall area of the specimen;

$\mathrm{h}=$ heat transfer coefficient;

$\mathrm{T}_{\mathrm{w}}=$ specimen wall temperature;

$\mathrm{T}_{\mathrm{a} w}=$ adiabatic wall temperature of the cooling fluid.

The adiabatic wall temperature is used in gas flows whenever the kinetic energy is significant compared to enthalpy changes (Rohsenow and Choi, 1961). Friction can cause the local wall temperature to exceed the bulk fluid temperature for an adiabatic specimen, and the adiabatic wall temperature approximates this effect. It is defined as

$$
\mathrm{T}_{\mathrm{aw}}=\mathrm{T}_{\mathrm{f}}+r \mathrm{~V}^{2} /\left(2 \mathrm{c}_{\mathrm{p}}\right)
$$

where $\mathrm{T}_{\mathrm{f}}=$ local bulk fluid temperature; $r=$ recovery factor $=\mathrm{Pr}^{1 / 3}$ for turbulent flow.

Adiabatic heating 'can be on the order of $1 \mathrm{~K}$ for the anticipated conditions. The local heat flux in eq (5) is expressed in terms of the total heat transfer to the specimen, $Q_{T}$, the total wetted wall area, and the furnace calibration function, $f_{q}$, which is a dimensionless expression of the local normal heat flux:

$$
q_{w}=\left(Q_{T} / A_{n}\right) \cdot f_{q} \cdot\left(A_{n} / A_{W}\right) .
$$


The wall temperature used in eq insulated side of the specimen.

(5) is measured with a thermocouple on the

In the defining equation of $h$ we assume (1) that the heat flux is uniform into the cooling fluid at a particular location (the same at the top and bottom surfaces and at the pins joining the top and bottom), (2) that the wall temperature is uniform, and hence (3) that the heat transfer coefficient is constant. However, since the specimen is heated from one side only and heat must flow through the specimen structure to enter the fluid from the pin and insulated wall, wall temperatures will not be constant. The dimensions of the specimen prevent instrumenting around the perimeter of a pin, and imbedded thermocouples alter the specimen temperature distribution, so the insulatedside thermocouple is used as the wall temperature. A finite-element conduction analysis using anticipated values of the heat transfer coefficient and the pin-fin configuration of figure 1 indicated that the temperature along the insulated side varies by $0.1 \mathrm{~K}$ or less with respect to pin position (for $50 \mathrm{~W} / \mathrm{cm}^{2}$ hot side heat $\mathrm{flux}$ ). In addition, the analysis indicated that the temperature of the insulated side is very close to the fluid-wall interface temperature along the bottom surface (within $\pm 1 \mathrm{~K}$ for a pin-fin specimen with $50 \mathrm{~W} / \mathrm{cm}^{2}$ hot side heat flux). This compares with a temperature difference between the wall and bulk fluid of at least $10 \mathrm{~K}$ for the same conditions. These conclusions could change for specimen geometries and materials different from those of the pin-fin configuration.

Combining eqs (5), (6) and (7) and rearranging, we get

$$
h=\frac{\left(Q_{T} / A_{w}\right) \cdot f_{q}}{\left\{T_{w}-\left[T_{f}+\left(r V^{2}\right) /\left(2 c_{p}\right)\right]\right\}} .
$$

We will calculate the heat transfer coefficient at all locations where temperature of the insulated side is measured with a thermocouple. We will measure the wall temperature directly, while the furnace calibration function $r_{q}$ is a function of location and heater voltage. The flow direction energy equation is used to calculate $Q_{T}$ (to follow). Gas temperature $T_{f}$ is calculated using the flow direction energy equation along with the furnace calibration (also to follow).

The total heat absorbed by the heat transfer specimen equals the total heat absorbed by the specimen plus manifolds, less the heat leak through the furnace insulation into the manifolds, $Q_{m}$. It is calculated from the temperatures of the gas inlet and outlet, the gas pressure drop, and an estimation of the manifold heat leak. Or

$$
\mathrm{Q}_{\mathrm{T}}=\dot{\mathrm{m}} \cdot\left(\mathrm{h}_{1}-\mathrm{h}_{0}\right)-\mathrm{Q}_{\mathrm{m}},
$$

where $\mathrm{h}=$ enthalpy;

$0=$ location in inlet manifold of PRT;

1 = location in outlet manifold of PRT;

$\mathrm{Q}_{\mathrm{m}}=$ heat leak to manifolds through insulation.

Heat absorbed by the manifold is typically 2-58 of the total heat flow, which we measured during calibrations on the furnace prior to inserting the test 
specimens. We neglect kinetic energy changes from 0 to 1 since they are insignificant compared to the uncertainties of the temperature measurement. The enthalpy change is given by

$$
\mathrm{h}_{1}-\mathrm{h}_{0}=\mathrm{c}_{\mathrm{p}} \cdot\left(\mathrm{T}_{1}-\mathrm{T}_{0}\right)+\int_{0}^{1}[(1-\beta \mathrm{T}) / \rho] \mathrm{dP},
$$

where $\beta=$ coefficient of thermal expansion.

The pressure term is significant since helium is not an ideal gas at these temperatures and pressures. The integral is evaluated using the virial equation of state for the gas (McCarty, 1973) and is included as a subroutine in the data analysis program. For that evaluation, pressure in the inlet and outlet manifold is required, although it is measured only at locations $A$ and B (fig. 3). Since the pressure term is usually less than 18 of the temperature term, pressure is assumed to vary linearly along the specimen and to be constant within the end manifolds. The ratio of the specimen length between taps $A$ and $B$ to the length between $A$ and 0 (the specimen inlet) is 8 . Thus, $P_{0}$ and $P_{1}$ are estimated as

$$
\begin{aligned}
& \mathrm{P}_{0}=\mathrm{P}_{\mathrm{A}}+\left(\mathrm{P}_{\mathrm{A}}-\mathrm{P}_{\mathrm{B}}\right) / 8 \\
& \mathrm{P}_{1}=\mathrm{P}_{\mathrm{B}}-\left(\mathrm{P}_{\mathrm{A}}-\mathrm{P}_{\mathrm{B}}\right) / 8
\end{aligned}
$$

Combining eqs (9) and (10) yield for $Q_{T}$ :

$$
\mathrm{Q}_{\mathrm{T}}=\dot{\mathrm{m}}\left\{\mathrm{c}_{\mathrm{p}} \cdot\left(\mathrm{T}_{1}-\mathrm{T}_{0}\right)+\int_{0}^{1}[(1-\beta \mathrm{T}) / \rho] \mathrm{dP}\right\}-\mathrm{Q}_{\mathrm{m}}
$$

The fluid temperature, $T_{f}$, is calculated by integrating the flow energy equation from the inlet manifold up to the location of interest (designated as $x)$, now including kinetic energy:

$$
T_{f x}=T_{0}+\frac{Q_{T} \cdot Q_{p x}}{\dot{m} c_{p}}+\frac{Q_{m, i n}}{\dot{m} c_{p}}-\frac{\int_{0}^{x}[(1-\beta T) / \rho] d P}{c_{p}}-\frac{V_{x}{ }^{2}}{2 c_{p}},
$$

where $\mathrm{Q}_{\mathrm{px}}=$ fraction of total heat flow on specimen added up to position $\mathrm{x}$;

= integration of furnace calibration function $\mathrm{f}_{\mathrm{q}}, 0$ to $\mathrm{x}$; $\mathrm{Q}_{\mathrm{m}, \text { in }}=$ heat leak to inlet manifold.

The fluid temperature requires the velocity at $x$, given by

$$
\mathrm{V}_{\mathrm{x}}=\dot{\mathrm{m}} /\left(\mathrm{A}_{\mathrm{f}} \rho_{\mathrm{x}}\right) \text {, }
$$

and the density is given by the equation of state (McCarty, 1973):

$$
\rho_{\mathrm{x}}=\rho_{\mathrm{x}}\left(\mathrm{T}_{\mathrm{fx}}, \mathrm{P}_{\mathrm{x}}\right) .
$$

The pressure at $\mathrm{x}$ is estimated by 


$$
P_{x}=P_{A}-\left(P_{A}-P_{B}\right) \cdot x / L
$$

With eq (16) substituted into eq (13) to evaluate the pressure term, eqs (13), (14), and (15) form a system of three equations in the unknowns of temperature, velocity, and density. They are solved through iteration by first neglecting velocity in eq (13) to calculate temperature; eq (15) is used to calculate density, eq (14) is used to calculate velocity, and temperature is re-calculated from eq (13) with velocity included. The iteration continues until convergence $(<0.01 \mathrm{~K}$ change in successive computations of temperature). Only two or three iterations are usually required since the kinetic energy is about $1 \%$ of the enthalpy change.

With $T_{f}$ and $V$ determined at location $x$, the heat transfer coefficient is calculated using eq (8). The Nusselt number, Prandtl number, and Reynolds number are then calculated:

$$
\begin{aligned}
& \mathrm{Nu}=\mathrm{h} \cdot \mathrm{D}_{\mathrm{H}} / \mathrm{k}, \\
& \operatorname{Pr}=\mu \cdot \mathrm{c}_{\mathrm{p}} / \mathrm{k} .
\end{aligned}
$$

The Eckert reference temperature is used to calculate the fluid properties due to the large wall to fluid temperature difference, as done by VanFossen (1982):

$$
\mathrm{T}_{\mathrm{r}}=0.5 \cdot \mathrm{T}_{\mathrm{w}}+0.28 \mathrm{~T}_{\mathrm{f}}+0.22 \mathrm{~T}_{\mathrm{aw}} .
$$

Fluid properties are calculated from the functions given in McCarty (1973).

4. Summary

We have described an apparatus which can measure the heat transfer and friction factor in thin, compact heat exchangers which are radiatively heated in a furnace at heat fluxes of up to $80 \mathrm{~W} / \mathrm{cm}^{2}$. Instrumentation and methods of data analysis are described. The apparatus will be used initially to test a compact heat exchanger of the pin-fin configuration using helium gas as the heat transfer fluid.

We acknowledge the assistance of Robert $R$. Wilson in performing the furnace calibration, developing data acquisition programs, and constructing the apparatus. We appreciate the assistance of David E. Daney in designing the apparatus. The thermocouple mounting technique for the pin-fin configuration was developed by NASA Langley Research Center. 


\section{References}

Armstrong, J., and Winstanley, D., 1987, "A Review of Staggered Array Pin Fin Heat Transfer for Turbine Cooling Applications," ASME paper 87-GT-201.

Buchmann, 0. A., Arefian, V. V., Warren, H. A., Vuigner, A. A., and Pohlman, M. J., 1985, "Advanced Fabrication Techniques for Hydrogen-Cooled Engine Structures," NASA CR-3949.

Kays, W. M., and London, A. L., 1964, Compact Heat Exchangers, McGraw-Hill, New York, 2nd. edition.

McCarty, Robert D., 1973, "Thermodynamic Properties of Helium 4 from 2 to 1500 $\mathrm{K}$ at Pressures to $10^{8} \mathrm{~Pa}, " \mathrm{~J}$. Phys. Chem. Ref. Data, Vol. 2, no. 4, pp. 9231042 .

Rohsenow, W. M., and Choi, H., 1961, Heat, Mass, and Momentum Transfer, Prentice-Hall, Inc., Englewood Cliffs.

Scotti, Stephen J., Martin, Carl J., and Lucas, Stephen H., 1988, "Active Cooling Design for Scramjet Engines Using Optimization Methods," NASA TM100581.

Shore, Charles P., 1986, "Review of Convectively Cooled Structures for Hypersonic Flight," NASA TM-87740.

Vanfossen, G. J., 1982, "Heat Transfer Coefficients for Staggered Arrays of Short Pin Fins," J. Eng. for Power, Vol. 104, pp. 268-274. 
Appendix A. Calibration of the heat-flux distribution within the furnace

Evaluation of the heat transfer performance of the specimens requires values for gas temperature inside the flow passages and for the local heat flux incident on the specimen. Neither of these will be measured directly during a test run with the specimen in place; the local gas temperature can be inferred from an energy balance on the gas if the heat flux to the specimen is known. Variations in heat flux across the furnace target area, the "heat flux distribution" are measured prior to the tests on the pin-fin specimens through tests on a "calibration specimen." For specimens with the same emissivity and thermal conductance to the heat sink, the furnace performance will not depend on the type of specimen receiving the heat flux.

\section{A.1. Description of the calibration apparatus}

To calibrate the furnace, the calibration specimen was placed in the target area of the furnace (see fig. A.1). Three heat flow meters soldered to the specimen measured the heat flow over the meter area, approximately 2.52 $\mathrm{cm}^{2}$. With the radiant heater at a steady voltage and with water cooling the specimen, the plate with meters attached was traversed over the furnace target area to measure variations in the $\mathrm{x}$ and $\mathrm{y}$ directions at that voltage. The readings from the meters were used only up to the point where the outer edge aligned with the furnace wall. The voltage was then changed and the $x-y$ traverse was repeated. The measured meter heat flow was then analyzed to give a heat flux, and a function for the heat flux was developed with inputs $x, y$, and heater voltage.

The calibration specimen consisted of a lower brass plate, $2.5 \mathrm{~cm}$ thick, and an upper copper plate, $0.64 \mathrm{~cm}$ thick. Cooling channels for water flow were machined in the brass piece. The plates were $12.7 \mathrm{~cm}$ wide and $33 \mathrm{~cm}$ long. The three heat flux meters were each $1.59 \mathrm{~cm}$ by $1.59 \mathrm{~cm}$ and $0.16 \mathrm{~cm}$ thick, and were located as shown in figure A.2. The signal lead wires lay in shallow channels machined in the top copper plate, and copper shading shims, also $0.16 \mathrm{~cm}$ thick, covered the leads to prevent overheating. The top surface of the assembled piece, including shims and heat flow meters, was spraypainted a flat black to provide a uniformly high absorptivity.

The calibration specimen was placed in a traversing mechanism which moved the specimen in the $x$ and $y$ directions in the plane of furnace target. In the $\mathrm{x}$ direction (parallel to the axis of the heater), the traversing mechanism could move all heat flow meters from one end of the furnace to the other. In the y direction (perpendicular to the axis of the furnace), motion was limited to about $3.8 \mathrm{~cm}$, sufficient to allow meters 2 and 3 to align with the ty wall, and meter 1 to align with the $-y$ wall. This allowed about $1.9 \mathrm{~cm}$ of meter overlap in the center; however each meter did not traverse the full y width. Position was read to $\pm 0.5 \mathrm{~mm}$. At maximum specimen displacement in the traversing mechanism (meters aligned with the furnace wall), coverage of the target by the specimen was $100 \%$.

The temperature of the calibration specimen was monitored with a type $K$ thermocouple placed under the left-side shim of figure A.2. Type K 
thermocouples monitored temperatures at an interior location of the furnace insulation, on the housing of the heater, and in the cooling air as it exited the heater. The heater voltage was also measured (as a percent of maximum voltage). The cooling water flow rate was monitored with a rotameter flowmeter, and the water temperature rise across the specimen was measured with thermistors.

\section{A.2. Operation of the heat flow meters}

The heat flow meters generated a DC voltage proportional to the heat flow through them. They consisted of three layers of metal; the top and bottom were the EP thermoelement, thermoelectrically different from the EN thermoelement in the middle layer. Flow of heat through the meter generated a temperature difference across the middle layer. Due to the alternating materials of construction, the temperature difference produced a voltage difference across the middle layer. Leads of the EP thermoelement were spotwelded to tabs on the top and bottom layers.

The manufacturer listed the uncertainty in the calibration of the meters as $\pm 5 \%$, with a linear relationship between heat flow and measured voltage output. As used in this application, though, they were not interchangeable. That is, if the plate was positioned such that each meter was exposed to the same heat flow, the output varied between meters by as much as $20 \%$. This variability was not due to an uncertainty of an individual meter calibration constant, but rather to differences in the calibration constant between meters. We found individual meters to be linear and repeatable to better than \pm 18 , over a range of heat fluxes from 0 to $44 \mathrm{~W} / \mathrm{cm}^{2}$, from calibrating the meters in a simple guarded hot plate apparatus. The calibration constant was also estimated with the meters attached to the calibration specimen. Using the heat absorbed in the cooling water as an estimate of the heat flow through the meter, the linearity for a single meter was about $\pm 2.5 \%$ for heat fluxes of 18 to $52 \mathrm{~W} / \mathrm{cm}^{2}$, which was the same as the uncertainty in the measurement of heat absorbed in the cooling water.

We believe differences in the calibration constants between meters are caused by: (1) variations in the thickness or thermal conductivity of the meter; (2) differences in the absorptivity between the meters; (3) variations in the thermal contact between the meter and copper plate for different meters. We think that (3) is the most likely; in the guarded hot plate apparatus we found that the agent bonding the meter to the cold sink affected the meter calibration. For example, the calibration constant differed by $15 \%$ for a meter soft-soldered to the cold sink and for a meter with indium compressed between the meter and cold sink.

As used in the furnace calibration, we obtained a relative calibration by assuming each meter was exposed to the same heat flow when located at the center of the furnace target. The voltage obtained at the center location was then used to normalize readings at locations off center. Based on the linearity and repeatability of the meters, the basic accuracy of the normalized reading was taken as $\pm 1 \%$. The uncertainty in the over-all heat flux distribution is evaluated below. 


\section{A.3. Methods of data analysis}

The heat flow meters measured the heat flow over a $2.52 \mathrm{~cm}^{2}$ area. For the specimen heat transfer experiments, heat flux (heat flow over an infinitesimal area) is required as a function of $\mathrm{x}$ position, $\mathrm{y}$ position, and the heater lamp voltage. It is more convenient to express this as

$$
q(x, y, v)=f_{q}(x, y, v) \cdot Q_{T} / A_{n},
$$

where $\mathrm{q}(\mathrm{x}, \mathrm{y}, \mathrm{v})=$ local heat flux based on the normal area;

$A_{\mathrm{n}}=$ specimen normal area;

$\mathrm{v}=$ heater voltage;

$\mathrm{f}_{\mathrm{q}}(\mathrm{x}, \mathrm{y}, \mathrm{v})=$ heat flux distribution function.

The quantity $\mathrm{Q}_{\mathrm{T}} / \mathrm{A}_{\mathrm{n}}$ is the average heat flux over the specimen. As re-stated, the problem now is to find $f_{q}$. The steps in determining the distribution function are

1) Measure the heat flow meter output (heat flow) over the target area (vs $\mathrm{x}$ and $\mathrm{y}$ ) for several heater voltages.

2) For each voltage, normalize the readings by the value of the meter output at the center of the target.

3) Fit a curve to the normalized data vs. $x$ and $y$.

4) Using the fitted curve, transform the data to extract the local normalized heat flux.

These steps are now explained in more detail.

The meter heat flow is equal to the measured voltage times a calibration constant, $\mathrm{K}$, or:

$$
j_{t}(x, y, v)=K \cdot V(x, y, v),
$$

with $j_{t}(x, y, v)=$ heat flow;

$\mathrm{V}(\mathrm{x}, \mathrm{y}, \mathrm{v})=$ the measured meter voltage.

By normalizing all the readings by the reading at the center of the furnace $(x=0, y=0)$, we can define another function:

$$
j(x, y, v)=V(x, y, v) / V(0,0, v)=j_{t}(x, y, v) / j_{t}(0,0, v) .
$$

This function, through the linearity of the meter, is also the ratio of heat flow at $x$ and $y$ to the heat flow at the furnace center. With values $j(x, y, v)$ at a few discrete points, typically a scan of $\mathrm{x}$ at constant $\mathrm{y}$ or a scan of $\mathrm{y}$ at constant $\mathrm{x}$, we fit a curve to the data using a least squares regression scheme to develop a polynomial function for $j(x, y, v)$. The data show that the variation in $j$ with $y$ is less than the uncertainty in the heat flow meter, so we neglect it and determine only a dependence of $j$ on $x$. For simplicity in the notation, the $\mathrm{v}$ argument is dropped also, with the understanding that the operations which follow occur at a constant voltage. 
We now define a function $f(x)$ which is the local heat flux normalized to he heat flux at $x=0$.

$$
f(x)=q(x) / q(0) .
$$

The function $j$ is thus the integration of $f$ over the meter area, or

$$
j(x) \cdot 2 w=\int_{x-w}^{x+w} f(\zeta) d \zeta,
$$

where $w$ is the half-width of the meter. If $f$ is constant or linear over the meter area, eq (A.5) will show that $j=f$. The relationship between $f$ and $f_{q}$ is found by combining (A.1) and (A.4):

$$
f(x) \cdot q(0)=q(x)=f_{q}(x) \cdot Q_{t} / A_{n} \cdot
$$

By integrating (A.6) over the total target area and equating to $Q_{t}$, it can be shown that:

$$
f_{q}(x)=\frac{f(x)}{\left[1 /\left(2 x_{0}\right)\right] \int_{-x_{0}}^{+x_{0}} f(\zeta) d \zeta}
$$

where $x_{0}$ is the half width of the target. Hence if we can find $f(x)$ through eq (A.5), eq (A.7) can be used to find the distribution function $f_{q}$ and eq (A.1) is used to find $q(x)$.

To find $f(x)$, we define a function $g$ such that

$$
j(x) \cdot 2 w=g(x+w)-g(x-w)=\int_{x-w}^{x+w} d[g(\zeta)]
$$

From eqs (A.5) and (A.8) we see that

$$
f(x)=d[g(x)] / d x
$$

Considering for the moment $x>0$, from eq (A.8), we can substitute $z=x+w$, and then

$$
g(z)=g(z-2 w)+2 w \cdot j(z-w) .
$$

The function $g$ at $z-2 w$ can be evaluated by recursion of eq (A.10), or

$$
g(z)=2 w \cdot j(z-w)+2 w \cdot j(z-3 w)+g(z-4 w) .
$$

And for an expansion of $n$ terms,

$$
f(z)=g^{\prime}(z)=2 w \cdot \sum_{i=1}^{n}\left\{j^{\prime}[z-(2 i-1) w]\right\}+f(z-2 n w)
$$


where eq (A.9) has been used where appropriate. The number of terms $n$ is chosen such that $-\mathrm{w}<z-2 \mathrm{nw}<\mathrm{w}$; that is, $\mathrm{f}(\mathrm{z}-2 \mathrm{nw})$ is evaluated around the center of the furnace target. The measurements show that $\mathrm{j}(\mathrm{x})$ is nearly linear near the target center, and $f$ can be taken equal to $j$ with little error. Or, replacing $z$ with $x$,

$$
f(x)=2 w \cdot \sum_{i=1}^{n}\left\{j^{\prime}[x-(2 i-1) w]\right\}+j(x-2 n w) .
$$

To evaluate $f$ at a location $x$, one sums up $j^{\prime}$ evaluated at $x-w, x-3 w, \ldots$ and adds to $j$ near $x=0$. It is easily shown that for $x<0$,

$$
f(x)=-2 w \cdot \sum_{i=1}^{n}\left\{j^{\prime}[x+(2 i-1) w]\right\}+j(x+2 n w)
$$

and $\mathrm{n}$ is chosen so that $-\mathrm{w}<\mathrm{x}+2 \mathrm{nw}<\mathrm{w}$.

In summary, $j(x)$ is calculated from the meter voltages for the measured points from eq (A.3) and fitted to a polynomial. The function $f(x)$ is calculated from eqs (A.13) and (A.14), and also fitted to a polynomial. Finally, $f_{q}$ is calculated from eq (A.7). The major advantages for using this technique (as opposed to using $j(x)$ directly) to determine the calibration function are two-fold. First, if the actual heat flux varies with $x$ in a nonlinear manner, the measured $j$ is not equal to $f$. This occurs near the end walls in the furnace, as the results of the next section will show. Second, the method allows for extrapolating to the furnace wall $\left(x= \pm x_{0}\right)$, even though the heat flow meter, when aligned with the wall, gives a heat flow centered at distance $w$ from the wall. This is because $j^{\prime}(x)$ represents the change in heat flux between $(x+w)$ and $(x-w)$, and $j$ at a meter half-width from the wall gives $f$ at the wall.

\section{A.4. Results of the calibration}

We calibrated the furnace at a range of heater lamp voltages from $20 \%$ of full voltage to 50 \% of full voltage. Very roughly, the heat flux on the target is linear with heater voltage; $50 \%$ of full voltage corresponds to about $50 \mathrm{~W} / \mathrm{cm}^{2}$ of heat flux on the target. At a single calibration, we held the heater voltage constant and measured heat flow through the meters over a representative portion of the furnace target. Voltages below 208 were not calibrated as they corresponded to heat fluxes lower than necessary for the heat transfer experiments, and voltages above $50 \%$ were not calibrated to avoid overheating the heat flow meters. The calibration tests are summarized in table A.1. We repeated the tests at voltages of $20 \%, 35 \%$, and $50 \%$ to assess the reproducibility of the data. At the 358 voltage level, we conducted calibrations at several levels of air cooling of the heater to determine whether the cooling rate had an effect on the calibration.

We present results in terms of the measured normalized heat flow through the heat flow meters ( $j$ of the previous section) plotted as a function of the 
position variables $\mathrm{x}$ and $\mathrm{y}$. This indicates the trends of the data. Curve fits of the heat flow data are plotted where appropriate, and the calibration equations ( $f_{q}$ function) for the dimensionless heat flux are presented.

Table A.1. Summary of furnace calibration experiments

\begin{tabular}{|c|c|c|c|c|}
\hline $\begin{array}{l}\text { Test } \\
\text { Number }\end{array}$ & Date & $\begin{array}{l}\text { Heater } \\
\text { Voltage }\end{array}$ & $\begin{array}{l}\text { Type of } \\
\text { Scan }\end{array}$ & Comments \\
\hline \multirow[t]{2}{*}{1} & $6 / 13 / 88$ & 35.38 & $\mathrm{x}-\mathrm{scan}$ & $\begin{array}{l}\text { Scan at } y=0 \text { and both } \\
\text { side walls. }\end{array}$ \\
\hline & & $35.3 \%$ & $y-s c a n$ & $\begin{array}{l}\text { Scan at } x=0 \text { and both } \\
\text { end walls. }\end{array}$ \\
\hline \multirow[t]{2}{*}{2} & $6 / 22 / 88$ & 35.38 & $x-s c a n$ & $\begin{array}{l}y=0 ; 3 \text { cooling air } \\
\text { flow settings. }\end{array}$ \\
\hline & & & $\mathrm{y}-\mathrm{scan}$ & $x=0$ \\
\hline \multirow[t]{2}{*}{3} & $6 / 23 / 88$ & 19.98 & $x-\operatorname{scan}$ & $y=0$ \\
\hline & & & $y-\operatorname{scan}$ & $x=0$ \\
\hline \multirow[t]{2}{*}{4} & $6 / 23 / 88$ & $50.8 \%$ & $x-\operatorname{scan}$ & $y=0$ \\
\hline & & & $y-\operatorname{scan}$ & $x=0$ \\
\hline 5 & $8 / 16 / 88$ & 35.48 & $x-s c a n$ & $\begin{array}{l}y=0 ; 2 \text { cooling air } \\
\text { flow settings. }\end{array}$ \\
\hline 6 & $8 / 18 / 88$ & 20.48 & $x-s c a n$ & $y=0$ \\
\hline 7 & $8 / 18 / 88$ & 35.28 & $\mathrm{x}-\mathrm{scan}$ & $y=0$. \\
\hline 8 & $8 / 18 / 88$ & $50.0 \%$ & $x-s c a n$ & $y=0$. \\
\hline 9 & $9 / 06 / 88$ & 20.28 & $\mathrm{x}-\mathrm{scan}$ & $y=0$ \\
\hline 10 & $9 / 06 / 88$ & 24.58 & $x-s c a n$ & $y=0$ \\
\hline 11 & $9 / 06 / 88$ & 29.38 & $x-s c a n$ & $y=0$ \\
\hline 12 & $9 / 06 / 88$ & 35.28 & $\mathrm{x}-\mathrm{scan}$ & $y=0$ \\
\hline
\end{tabular}

Traverses in the $\mathrm{y}$ (short) direction of the furnace indicated uniform heat flow at all voltages tested. This can be seen in figure A.3, which shows the normalized meter heat flow ( $j$ function) from tests 2 and 3 , voltages $35 \%$ and $20 \%$ respectively. The scan was done near $x=0$, the midpoint of the furnace. Data from meters 1 and 2 are shown; the data overlap near $y=0$. There is about a $5 \%$ drop off in the meter output near the side-walls $( \pm 2.5 \%$ of the mean), but since this is of the same order as the meter calibration uncertainty, we neglect this effect in developing the calibration functions. In test 1 , the furnace was scanned in the y direction close to both end walls 
(large $\mathrm{x}$ and small $\mathrm{x}$ ). The results indicated the same uniformity in the heat flux for the $y$ direction as in figure A.3. Hence, we found no significant variation in heat flux in the $\mathrm{y}$ direction, regardless of heater voltage or $\mathrm{x}$ position in the furnace.

Scans in the $\mathrm{x}$ (long) direction showed variations with position and in some cases the heater voltage. Figure A.4 shows meter heat flow data for tests 2, 4, and 11 using heat flow meter \#3, at voltages of 35\%, 518, and 298 . This distribution was unsymmetric; the heat flow gradually increased from the negative $x$ end to the positive $x$ end, with a drop-off near both end walls. We measured this asymmetry for all voltages above $29 \%$, which we believe is due to the air cooling characteristics of the radiant heater. In the heater, cooling air flows around the lamp elements to prevent overheating; the cooling air flow direction is from the negative $x$ end to the positive $x$ end. In flowing along the lamps, the air heats up significantly. Hence the cooler lamps at the air inlet (negative $\mathrm{x}$ ) produce lower heat flux that the hotter lamps at the air outlet. Reversing the position of the heater relative to the furnace produced reverse asymmetry in the heat flow distribution.

A curve fitted to the data from tests 1,2 , and 4 is also shown in figure A.4, and the standard deviation of the residuals between the measured heat flow and the curve value is $0.5 \%$. Although the heat flow varies with $x$ position, we found no significant change in the distribution above $29 \%$ voltage. When data from later tests at voltages above $29 \%$ (tests 7, 8, 11 , and 12) was compared to the curve-fit from figure A.4, the standard deviations to the curve for these later tests ranged from $0.9 \%$ for test 11 to 1.38 for test 7 , indicating the repeatability of the furnace. In test 2 we varied the cooling air flow rate such that the temperature of the air exiting the heater changed from $175^{\circ} \mathrm{C}$ to $250^{\circ} \mathrm{C}$ (lower cooling air flow corresponding to higher air temperature). This had no significant effect on the heat flow distribution.

For heater voltages of $25 \%$ and lower, the furnace produced a symmetric heat flow distribution in the $\mathrm{x}$ direction. Figure A.5 shows scans in the $\mathrm{x}$ direction from tests 6, 9, and 10 for heater voltages of $20 \%$ and $25 \%$. Also shown is the curve fitted to the meter heat flow data ( $j$ function), which had a standard deviation of 0.38 from the measured data. The heat flow drops to about $85 \%$ of the maximum at the end walls. The variation in the $y$ direction was again no greater than that shown in figure A.3. We believe that at the low voltages, the heater lamps remain cool along their entire length, which results in the symmetric distribution.

The measured heat flow data for tests 1, 2, and 4 were analyzed to give the furnace distribution function $\left(f_{q}\right)$ for the unsymmetric profile (voltages greater than 29\%), and heat flow data from tests 6, 9, and 10 were analyzed to give the distribution function for the symmetric profile (voltages less than 298). The sixth-order polynomial curve-fit and the region of validity are summarized in table A.2. The actual heat flux at any $x$ and $y$ for a heater voltage $\mathrm{v}$ is then given by eq (A.1). 
Table A.2. Furnace heat flux distribution function, fq

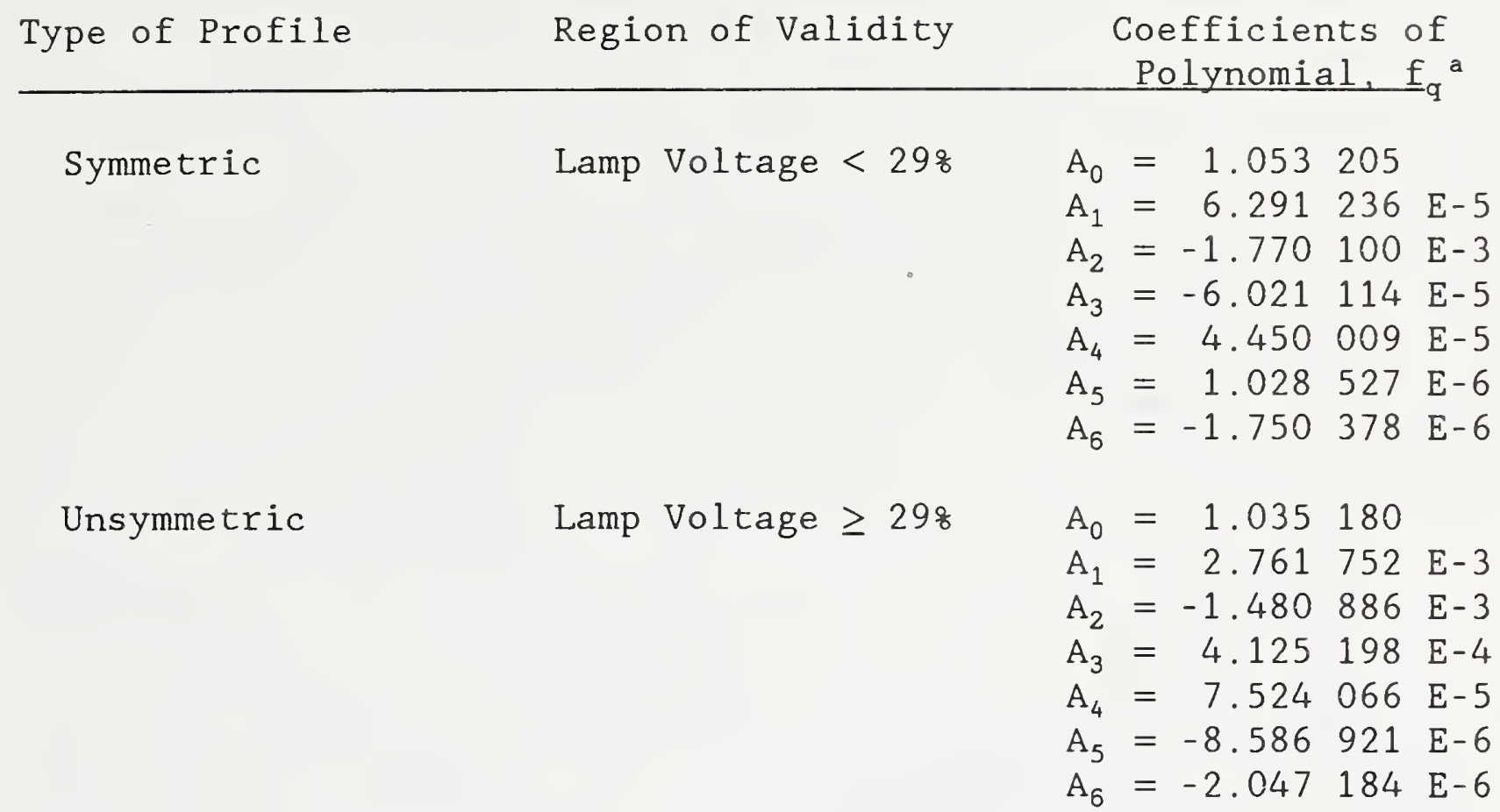

a where $f_{q}=A_{0}+A_{1} \cdot x+A_{2} \cdot x^{2}+A_{3} \cdot x^{3}+A_{4} \cdot x^{4}+A_{5} \cdot x^{5}+A_{6} \cdot x^{6}$ and $x$ is in $\mathrm{cm}$.

A.5. Uncertainty in the furnace heat flux calibration

The uncertainty in the heat flux distribution is estimated from the uncertainty in the heat flow meter measurement, $\sigma$, the uncertainty in the calibration function when compared to the measured heat flow data ( $3 \sigma)$, and from the reproducibility of the furnace calibration $(3 \sigma)$. The square root of the sum of the squares of these individual. uncertainties results in an uncertainty of about \pm 48 . 


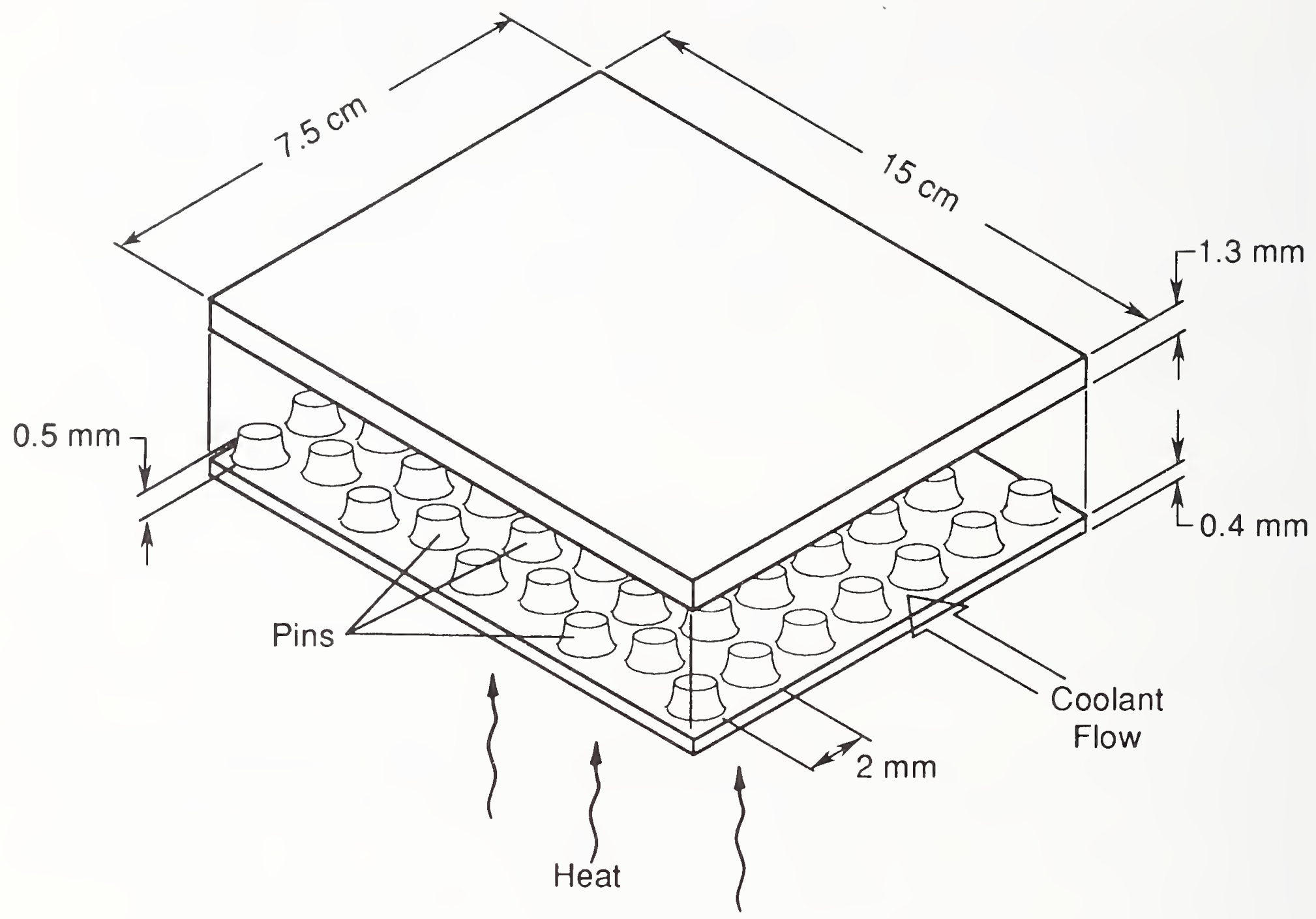

Figure 1. Pin-fin heat exchanger for NASP appíication (separated view). 


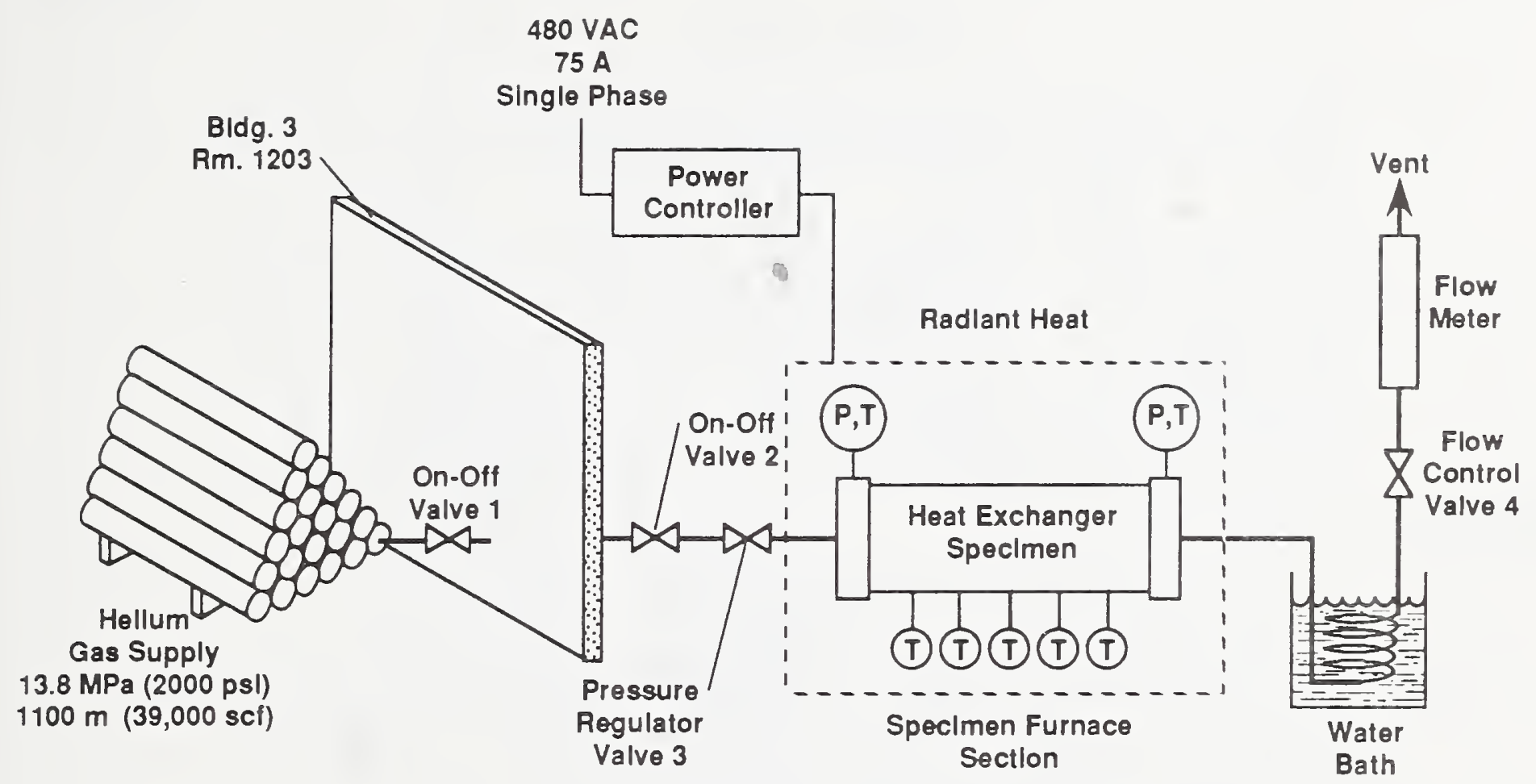

Figure 2. Helium flow loop. 


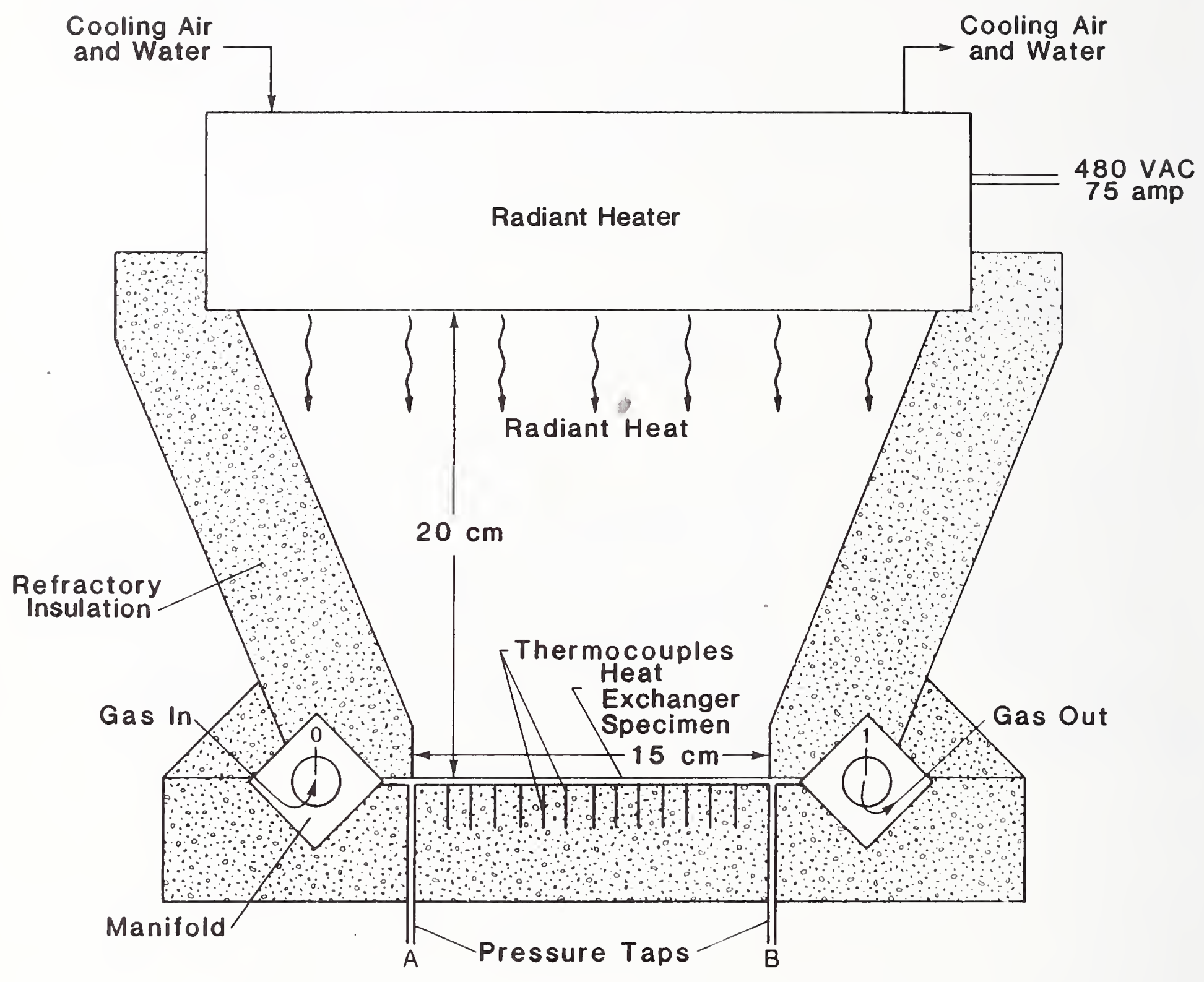

Figure 3. Specimen furnace. Inlet and outlet gas temperatures are measured at points 0 and 1 ; upstream and downstream pressures are measured at points $A$ and $B$. 


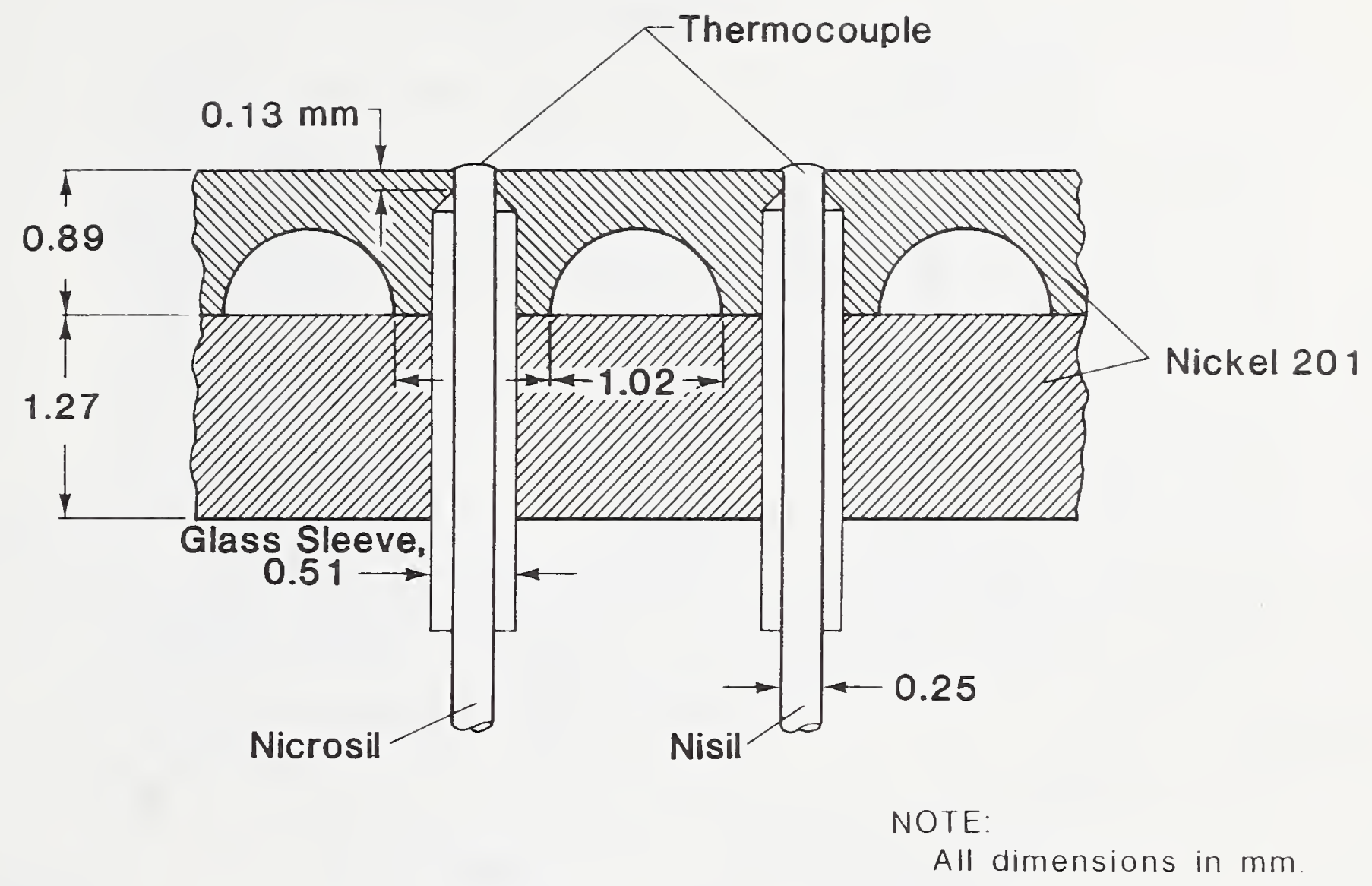

Figure 4. Technique for mounting thermocouples on pin-fin specimens. 


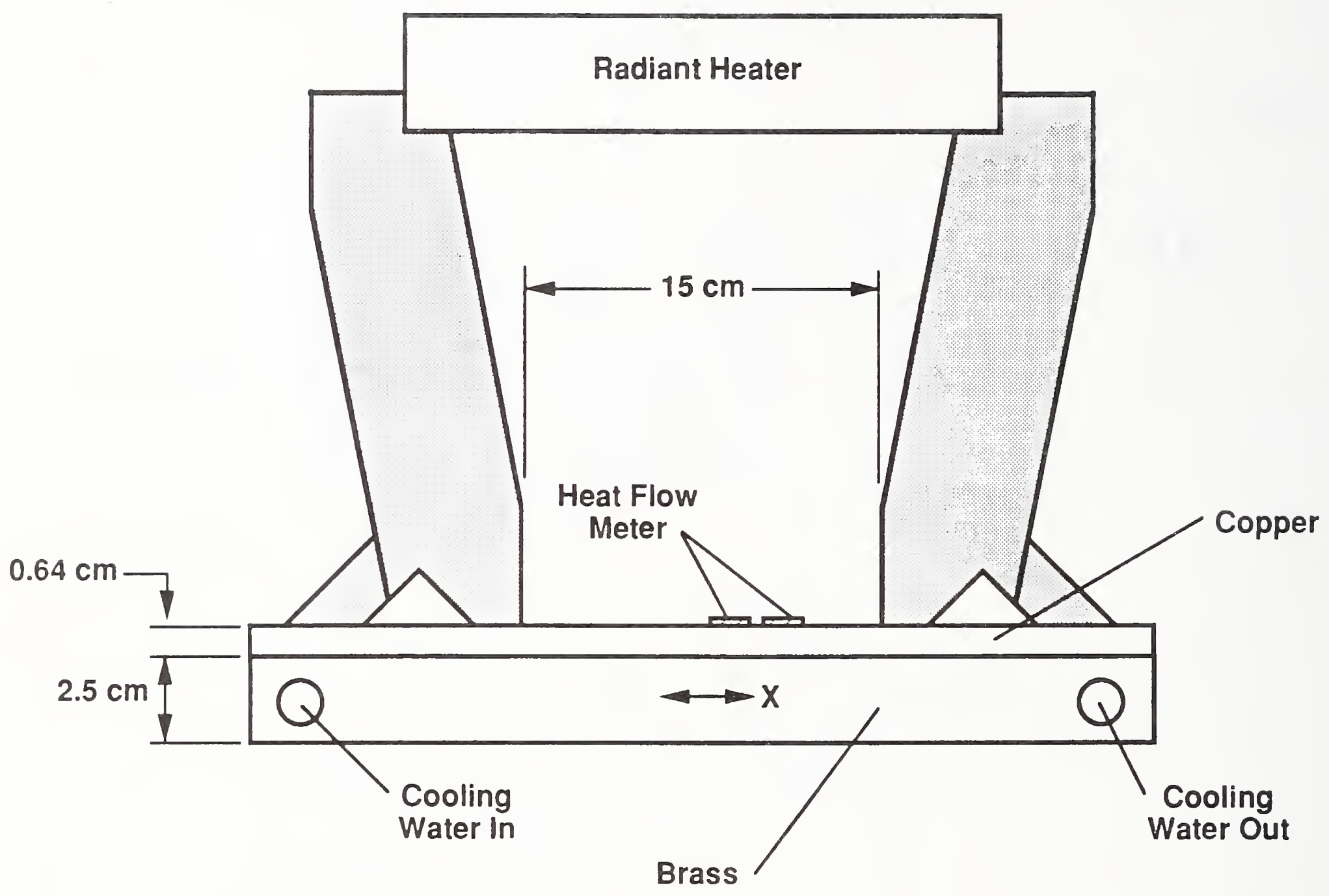

Figure A.1. Calibration specimen in furnace. 


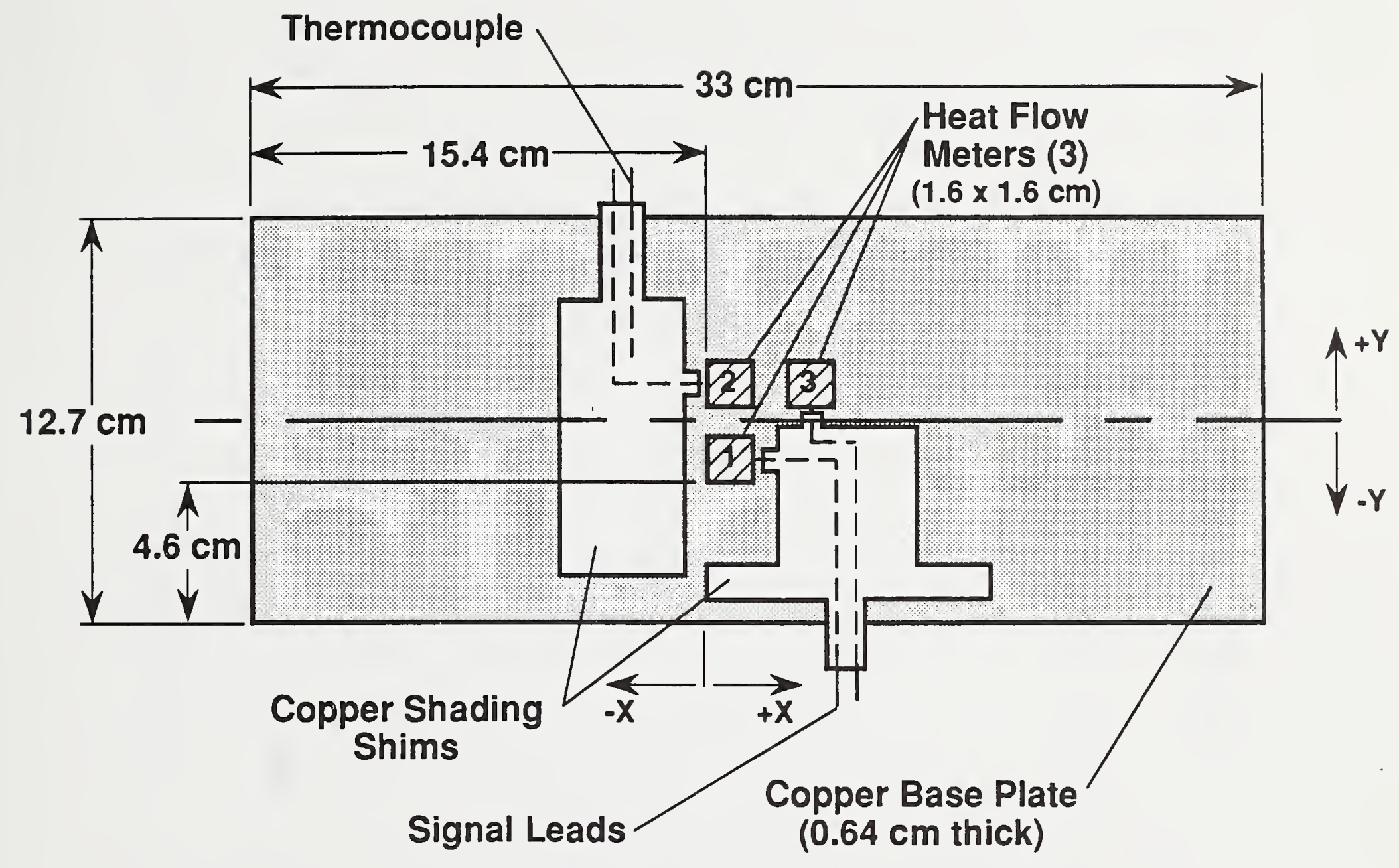

Figure A.2. Lay-out of heat flow meters on calibration specimen. 


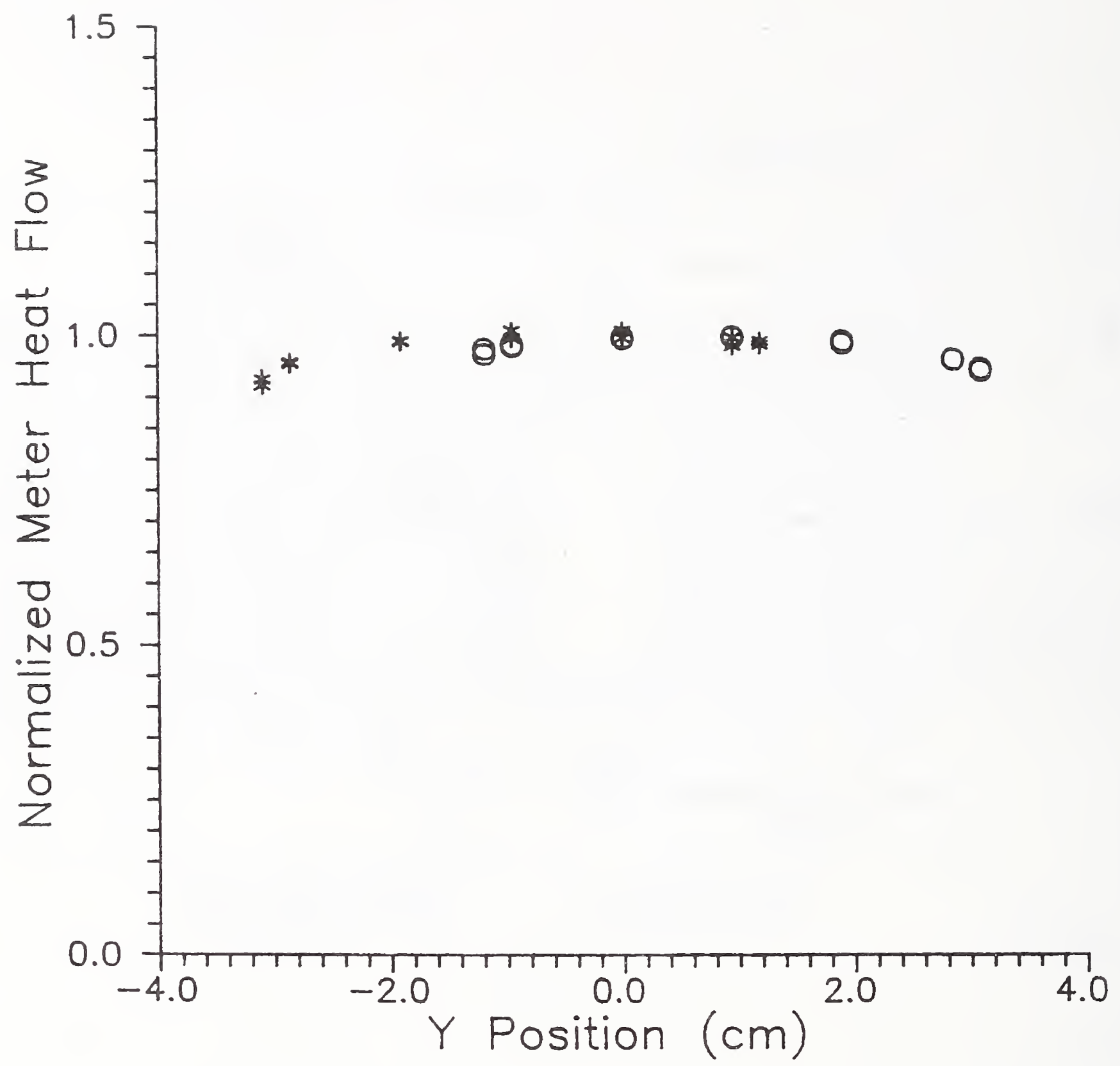

Figure A.3. Traverse of normalized heat flow along $y$ direction at $x=0$. Shown are data from tests 2 and 3 , heater voltages 35.38 and 19.98. "*" is meter 1 , and "o" is meter 2 . 


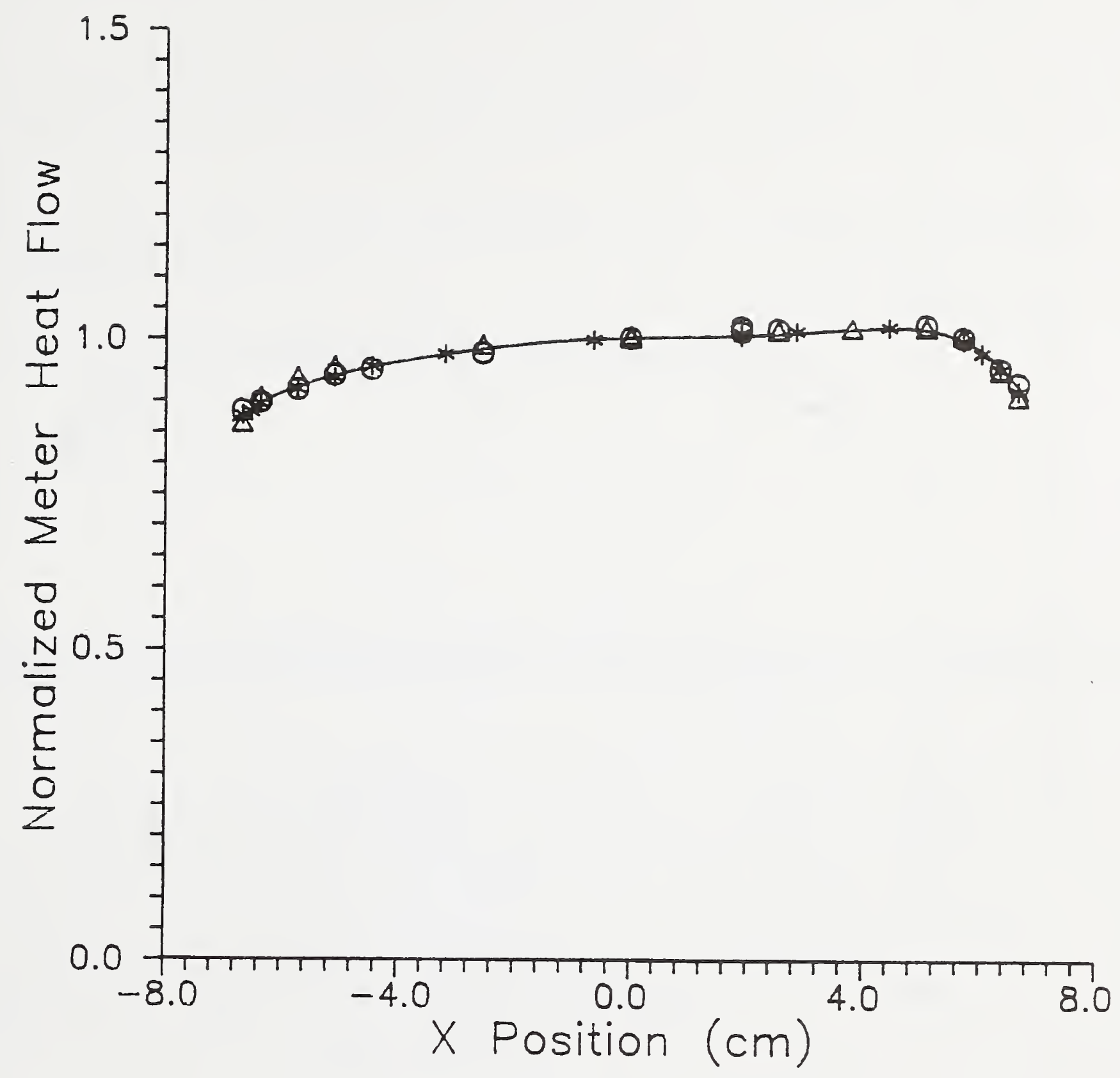

Figure A.4. Traverse of normalized heat flow along $x$ direction at $y=0$ for heater voltages greater than 298. Shown are data from test 2 ( 35.38 voltage, "*"), test 4 (50.8\% voltage, "o"), and test 11 (29.38 voltage, " $\Delta ")$. The smooth curve is the curve fitted to the normalized heat flow data ( $j$ function), which has a standard deviation of 0.58 . 


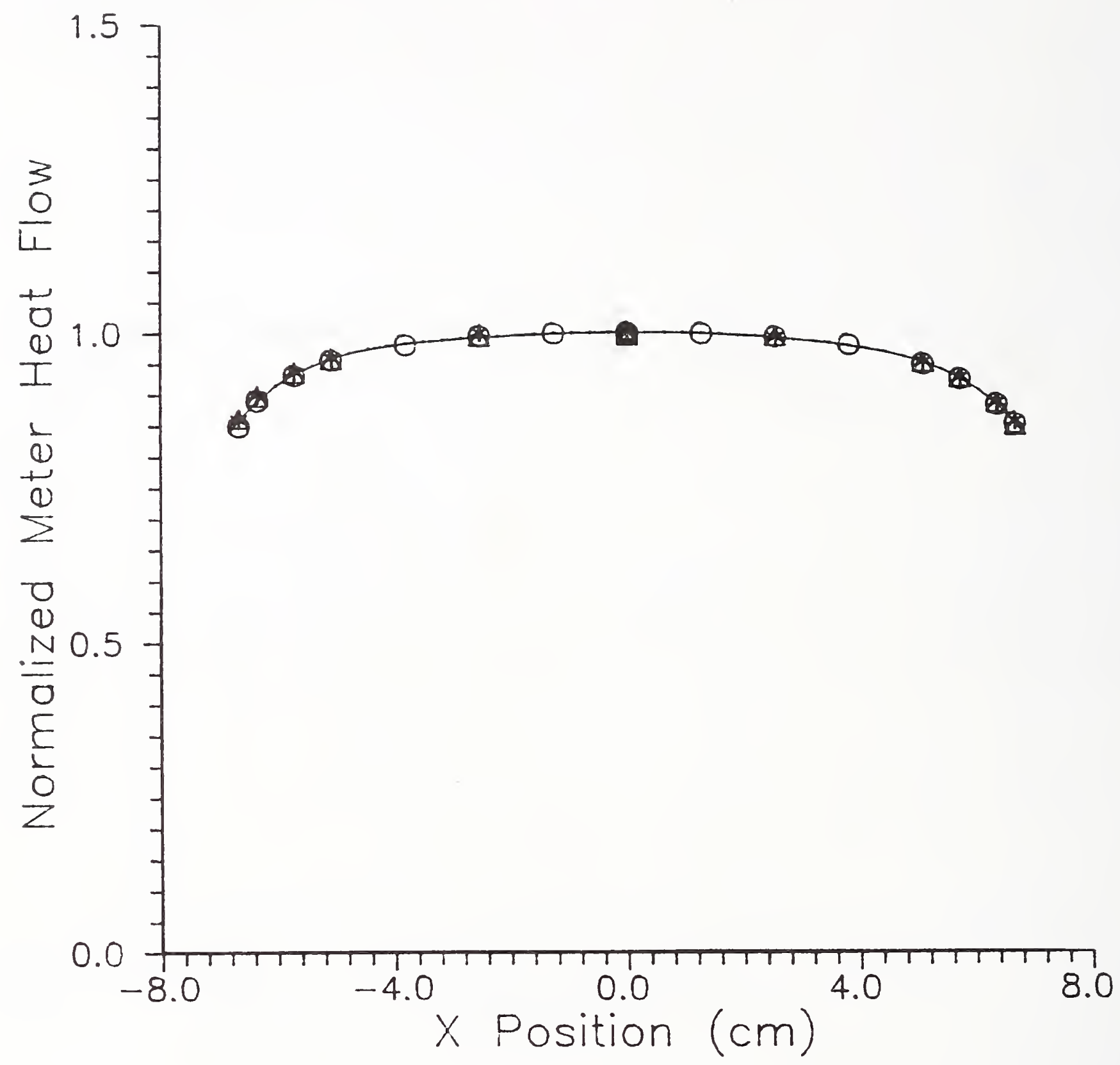

Figure A.5. Traverse of normalized heat flow along $\mathrm{x}$ direction at $\mathrm{y}=0$ for heater voltages less than 29\%. Shown are data from test 6 (20.48 voltage, "*"), test 9 (20.28 voltage, "o"), and test 10 (24.58 voltage, " $\Delta "$ ). The smooth curve is the curve fitted to the normalized heat flow data ( $j$ function), which has a standard deviation of $0.3 \%$. 
IST-114A

IEV. 3-89)
U.S. DEPARTMENT OF COMMERCE

NÄTIONAL INSTITUTE OF STANDARDS AND TECHNOLOGY

BIBLIOGRAPHIC DATA SHEET
1. PUBLICATION OR REPORT NUMBER

NISTIR 89-3926

2. PERFORMING ORGANIZATION REPORT NUMBER

3. PUBLICATION DATE

October 1989

\section{TITLE AND SUBTITLE}

APPARATUS FOR MEASURING HIGH-FLUX HEAT TRANSFER IN RADIATIVELY HEATED COMPACT EXCHANGERS AUTHOR(S)

Douglas A. Olson

\begin{tabular}{|c|c|}
\hline PERFORMING ORGANIZATION (IF JOINT OR OTHER THAN NIST, SEE INSTRUCTIONS) & 7. CONTRACT/GRANT NUMBER \\
\hline $\begin{array}{l}\text { U.S. DEPARTMENT OF COMMERCE } \\
\text { MATIONAL INSTITUTE OF STANDARDS AND TECHNOLOGY } \\
\text { GAITHERSBURG, MD } 20899\end{array}$ & 8. TYPE OF REPORT AMD PEAIOD COVERED \\
\hline
\end{tabular}
SPONSORING ORGANIZATION NAME AND COMPLETE ADDRESS (STREET, CITY, STATE, ZIP)

National Aeronautics and Space Administration

Langley Research Center

Hampton, Virginia 23665

\section{SUPPLEMENTARY NOTES}

DOCUMENT DESCRIBES A COMPUTER PROGRAM; SF-185, FIPS SOFTWARE SUMMARY, IS ATTACHED.

I. ABSTRACT (A 200-WORD OR LESS FACTUAL SUMMARY OF MOST SIGNIFICANT INFORMATION. IF DOCUMENT INCLUDES A SIGNIFICANT BIBLIOGRAPHY OR LITERATURE SURVEY, MENTION IT HERE.)

We describe an apparatus which can deliver uniform heat flux densities of up to $80 \mathrm{~W} / \mathrm{cm}^{2}$ over an area $7.8 \mathrm{~cm}$ by $15.2 \mathrm{~cm}$ for use in measuring the heat transfer and pressure drop in thin ( $6 \mathrm{~mm}$ or less), compact heat exchangers. Helium gas at flow rates of 0 to $40 \mathrm{~kg} / \mathrm{h}$ and pressures to $6.9 \mathrm{MPa}$ (1000 psi) is the working fluid. We describe the instrumentation used in the apparatus and the methods for analyzing the data. We will use the apparatus initially to test the performance of prototype cooling jackets for the engine struts of the National Aerospace Plane (NASP).

KEY WORDS (6 TO 12 ENTRIES; ALPHABETICAL ORDER; CAPITALIZE ONLY PROPER NAMES; AND SEPARATE KEY WORDS BY SEMICOLONS)

apparatus; compact heat exchanger; convection heat transfer; friction factor; high temperatures; National Aerospace Plane; pin-fin; radiative furnace.

\section{AVAILABILITY}

$\mathrm{X}$

UNLIMITED

FOR OFFICIAL DISTRIBUTION. DO NOT RELEASE TO NATIONAL TECHNICAL INFORMATION SERVICE (NTIS).

ORDER FROM SUPERINTENDENT OF DOCUMENTS, U.S. GOVERNMENT PRINTING OFFICE, WASHINGTON, DC 20402.

ORDER FROM NATIONAL TECHNICAL INFORMATION SERVICE (NTIS), SPRINGFIELD, VA 22161.
14. NUNBER OF PRINTEO FAGES

40 


